\title{
Association between a functional genetic polymorphism (rs2230199) and age-related macular degeneration risk: a meta-analysis
}

\author{
M.X. Zhang ${ }^{1,2 *}$, X.F. Zhao ${ }^{3 *}$, Y.C. Ren ${ }^{1,2}$, T.T. Geng ${ }^{2,5}$, H. Yang ${ }^{1,2}$, T. Feng ${ }^{2}$, \\ T.B. Jin ${ }^{1,2,4}$ and C. Chen ${ }^{1,2}$ \\ ${ }^{1}$ School of Life Sciences, Northwest University, Xi'an, China \\ ${ }^{2}$ National Engineering Research Center for Miniaturized Detection Systems, \\ Xi'an, China \\ ${ }^{3}$ The Military Area General Armed Police Hospital, Beijing, China \\ ${ }^{4}$ Key Laboratory of High Altitude Environment and Genes Related to Diseases of \\ Tibet Autonomous Region, School of Medicine, Xizang Minzu University, \\ Xianyang, Shaanxi, China \\ ${ }^{5}$ Department of Endocrinology, First Affiliated Hospital, Xi'an Jiaotong University, \\ Xi'an, China \\ *These authors contributed equally to this study. \\ Corresponding authors: T.B. Jin / C. Chen \\ E-mail: tianbojin1975@163.com / cchen898@nwu.edu.cn
}

Genet. Mol. Res. 14 (4): 12567-12576 (2015)

Received May 27, 2015

Accepted August 20, 2015

Published October 16, 2015

DOI http://dx.doi.org/10.4238/2015.October.16.24

ABSTRACT. The association between the rs2230199 C>G single nucleotide polymorphism (SNP) in complement component 3 and agerelated macular degeneration (AMD) risk has been examined extensively but the results are not consistent among studies. The aim of this study was to perform a meta-analysis of all available studies on this SNP in relation to AMD. The comprehensive databases of PubMed, Medline, Web of Knowledge, CNKI, and Google Scholar were searched for case-control studies investigating the association between the rs2230199 polymorphism and AMD susceptibility. ORs with $95 \% \mathrm{Cls}$ were estimated to assess the 
association. Sensitivity analysis, test of heterogeneity, cumulative metaanalysis, and assessment of bias were also performed. A total of 15 published studies including 5593 cases and 5181 controls were used in this meta-analysis. Overall, the rs2230299 SNP was significantly associated with the risk of $A M D$ in the overall population under the additive model $(\mathrm{OR}=1.571,95 \% \mathrm{Cl}=1.414-1.745, \mathrm{P}=0.000)$, dominant model $(\mathrm{OR}=$ $1.681,95 \% \mathrm{Cl}=1.521-1.858, \mathrm{P}=0.000)$, and allelic model $(\mathrm{OR}=1.597$, $95 \% \mathrm{Cl}=1.470-1.734, \mathrm{P}=0.000)$. In the subgroup analysis by ethnicity, the same results were found in Caucasian populations, while no significant correlations were found in Asian populations for all comparison models. In conclusion, our meta-analysis provides evidence that the rs2230199 polymorphism contributes to the development of AMD. Further large-scale multicenter epidemiological studies are warranted to confirm this finding.

Key words: Polymorphism; Age-related macular degeneration; Rs2230199; Meta-analysis

\section{INTRODUCTION}

Age-related macular degeneration (AMD) is a retinal disorder that causes blindness in individuals over 50 years of age and is the third leading cause of global blindness (Resnikoff et al., 2004; De Jong, 2006). There are 2 main types of AMD: neovascular AMD (NV-AMD), characterized by invasion of the subpigment epithelial and subretinal spaces by neovascular complexes (this is known as choroidal neovascularization), and geographic atrophy (GA), characterized by extensive loss of the choriocapillaris and the overlying retinal pigment epithelium (Yanagisawa et al., 2011). AMD has a relatively high prevalence in developed countries and has become a major public health issue. It is estimated that more than 33 million people worldwide develop vision loss due to AMD (Duvvari et al., 2014). As with other human diseases, AMD is a complex disease with environmental and genetic factors impacting its development. The strongest identifiable risk factors for AMD are age, family history, smoking, and genetics (Gehrs et al., 2010). Although the precise etiology of AMD remains elusive, genetic studies have provided insights into the molecular basis of AMD. In the last decade, it has been found that genetic factors are involved in the pathogenesis of AMD alongside other risk factors such as smoking, diet, and overexposure to sunlight (Mousavi and Armstrong, 2013). AMD has been convincingly shown to be associated with two adjacent genes on chromosome 10q26: age-related maculopathy susceptibility 2 (ARMS2) and high-temperature requirement factor H (HTRA1) (Gold et al., 2006; McKay et al., 2010). Together, mutations in these genes account for nearly half of the heritability of AMD (Vingerling et al., 1995). In addition, rare, highly penetrant variants in the genes encoding complement factor $\mathrm{H}(\mathrm{CFH})$, complement factor I (CFI), complement component 3 (C3) and complement component 9 (C9) have recently been found to be associated with AMD (Raychaudhuri et al., 2011; Seddon et al., 2013).

The C3 gene, located on chromosome 19, has 2 single nucleotide polymorphisms (SNPs), rs2230199 C > G and rs1047286 G > A, reported to be highly associated with AMD (Park et al., 2009). Furthermore, complement component 3 (CC3) is a plausible candidate since its cleavage product, $\mathrm{C} 3 \mathrm{a}$, has been found in drusen. These findings strongly implicate aberrant regulation and/or activation of the complement pathway in the mechanism of susceptibility to AMD. Several 
studies have reported associations between the rs2230199 SNP and the risk of AMD. However, because single studies are often underpowered due to inadequate sample sizes, the results from past studies are inconclusive. Therefore, we performed a meta-analysis to more precisely characterize the association between the rs2230199 polymorphism and AMD.

\section{MATERIAL AND METHODS}

\section{Search strategy}

We searched five electronic databases (PubMed, Medline, Web of Knowledge, CNKI, and Google Scholar) to identify eligible studies that were published before October 2014. Articles were identified using the following search strategy: ("gene" or "allele" or "polymorphism") and ("agerelated macular degeneration") and ("complement component 3" or "C3" or "complement factor 3"). All potentially eligible studies were retrieved and their bibliographies were carefully evaluated to identify other eligible research. Only studies published in the English language were included. Where there were multiple publications from the same study group, the most complete and recent results were used.

\section{Inclusion and exclusion criteria}

The following inclusion criteria were observed when selecting literature for further metaanalysis: 1) an independent case-control study that quantitatively assessed the relationship between the risk of AMD and the rs2230199 polymorphism; and 2) sufficient available data to estimate the OR with $95 \% \mathrm{Cl}$. Where eligible papers provided insufficient information, we contacted authors by e-mail for additional information. Major exclusion criteria were as follows: 1) no control population, 2) duplication of a previous study, and 3) no available genotype frequency. Finally, the data for the analysis were available from 15 case-control studies, including 5593 cases of AMD and 5181 healthy controls for the C3 rs2230199 polymorphism.

\section{Data extraction}

Two investigators independently extracted data and reached a consensus on all of the items. The following information was extracted from each study: first author, publication year, ethnicity (country), source of controls, number of cases and controls, characteristics of the participants, and the genotype frequencies of the cases and controls.

\section{Statistical analysis}

The strength of association between the rs2230199 polymorphism and AMD risk was assessed by OR with the corresponding $95 \% \mathrm{Cl}$ for each study. Based on the individual ORs, the pooled OR was estimated. Different ORs were calculated using the following models: the allele model ( $G$ vs $C$ ), the additive genetic model ( $G G$ vs $C G$ or $C G$ vs $C C$ ), the dominant genetic model ( $C G+G G$ vs $C C)$, and the recessive genetic model ( $G G$ vs $C C+C G$ ). Heterogeneity assumption was evaluated with a chi-square-based $Q$-test. If the $P$ value is greater than 0.100 of the $Q$-test, which indicates a lack of heterogeneity among studies, the summary OR estimate of each 
study was calculated by the Mantel-Haenszel fixed effects model (Mantel and Haenszel, 1959). Otherwise, the DerSimoniane and Laird random-effects method (DerSimonian and Laird, 1986) was performed. The heterogeneity was also assessed using the $\mathrm{I}^{2}$-test (Zintzaras and loannidis, 2005), which takes values between $0 \%$ and $100 \%$ with higher values denoting greater degree of heterogeneity $\left(I^{2}=0-25 \%\right.$ : no heterogeneity; $I^{2}=25-50 \%$ : moderate heterogeneity; $I^{2}=50-75 \%$ : large heterogeneity; $I^{2}=75-100 \%$ : extreme heterogeneity). The significance of the pooled OR was determined using the Z-test.

To explore the reasons for heterogeneity, subgroup analyses were performed by grouping studies that showed similar characteristics, such as ethnicity and control source. For the sensitivity analysis, each study was removed in turn from the compiled list and the remaining studies were reanalyzed to assess the stability of the results. Funnel plots, Begg's test, and Egger's test were used to obtain diagnosis of the potential publication bias. All statistical analysis was performed with the Stata software (version 11.0; StataCorp LP, College Station, TX, USA) using two-sided P values. P < 0.05 was considered statistically significant in all analyses except for the heterogeneity test.

\section{RESULTS}

\section{Characteristics of the included studies}

According to the criteria for inclusion and exclusion, 15 case-control studies investigating the association between the rs2230199 polymorphism and risk of AMD were included in the present meta-analysis. The flow diagram of the literature search strategy is shown in Figure 1. Of the 15 studies, 10 studies were conducted in Caucasian populations and 5 conducted in Asian populations. Five of the studies used a population-based design and 10 studies used a hospitalbased design. The genotype frequencies of the C3 rs2230199 polymorphism were extracted from the studies. The rs2230199 genotype distributions in the controls from all of the studies conformed to the Hardy-Weinberg equilibrium. The main characteristics of the studies are listed in Table 1.

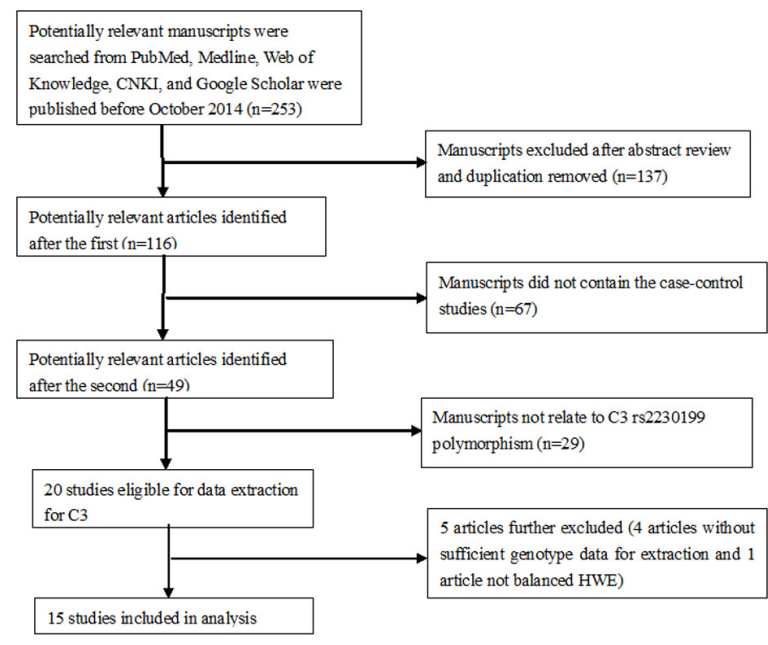

Figure 1. Literature search flow chart. 


\begin{tabular}{|c|c|c|c|c|c|c|c|c|}
\hline \multirow{2}{*}{$\begin{array}{l}\text { First author } \\
\text { (Reference) }\end{array}$} & \multirow[t]{2}{*}{ Publication year } & \multirow[t]{2}{*}{ Location } & \multirow[t]{2}{*}{ Ethnicity } & \multirow[t]{2}{*}{ Source of control } & \multicolumn{2}{|c|}{ Sample size } & \multirow[t]{2}{*}{ Genotype method } & \multirow[t]{2}{*}{ HWE } \\
\hline & & & & & Case & Control & & \\
\hline Wu et al. (2013) & 2012 & China & Asian & $\mathrm{HB}$ & 165 & 216 & Taqman & 0.891 \\
\hline Tian et al. (2012) & 2012 & China & Asian & $\mathrm{HB}$ & 532 & 465 & MassARRAY Compact System & 0.963 \\
\hline Liu et al. (2010) & 2010 & China & Asian & PB & 238 & 220 & Genemapper software & 0.892 \\
\hline Cui et al. (2010) & 2009 & China & Asian & $\mathrm{HB}$ & 150 & 161 & PCR-RFLP & 0.968 \\
\hline Pei et al. (2009) & 2009 & China & Asian & $\mathrm{HB}$ & 123 & 130 & MALDI-TOF MS & 0.859 \\
\hline Yu et al. (2011) & 2011 & USA & Caucasian & $\mathrm{HB}$ & 1074 & 216 & TaqMan & 0.942 \\
\hline Peter et al. (2011) & 2011 & New York & Caucasian & $\mathrm{HB}$ & 194 & 1260 & TaqMan & 0.574 \\
\hline McKay et al. (2010) & 2010 & UK & Caucasian & PB & 437 & 436 & $\begin{array}{l}\text { Multiplex PCR and primer } \\
\text { extension methodology }\end{array}$ & 0.117 \\
\hline Reynolds et al. (2009) & 2009 & USA & Caucasian & $\mathrm{HB}$ & 97 & 58 & MALDI-TOF MS & 0.812 \\
\hline Scholl et al. (2009) & 2009 & USA & Caucasian & PB & 97 & 584 & Sequencing & 0.273 \\
\hline Edwards et al. (2008) & 2008 & France & Caucasian & $\mathrm{HB}$ & 443 & 299 & $\begin{array}{l}\text { Genotyping module of the } \\
\text { BeadStudio } 3 \text { software }\end{array}$ & 0.097 \\
\hline Scholl et al. (2008) & 2008 & USA & Caucasian & $\mathrm{HB}$ & 112 & 67 & MALDI-TOF MS/Taqman & 0.826 \\
\hline Seitsonen et al. (2008) & 2008 & UK & Caucasian & $\mathrm{HB}$ & 151 & 105 & TaqMan & 0.671 \\
\hline Spencer et al. (2008) & 2008 & USA & Caucasian & PB & 701 & 286 & TaqMan & 0.943 \\
\hline Yates et al. (2007) & 2007 & UK & Caucasian & PB & 1079 & 678 & Taqman & 0.713 \\
\hline
\end{tabular}

$\mathrm{HB}=$ hospital-based; $\mathrm{PB}=$ population-based; HWE = Hardy-Weinberg equilibrium; PCR-RFLP = polymerase chain reaction and restrictive fragment length polymorphism; MALDI-TOF MS = matrix-assisted laser desorption/ionization time-of-flight mass spectrometry.

\section{Meta-analysis results}

Several genetic models were used in our meta-analysis and the main results are listed in Table 2. The results showed that there was a significant association between the rs2230199 SNP and $\mathrm{AMD}$ susceptibility in overall populations (allelic model: pooled $\mathrm{OR}=1.597$ for $\mathrm{G}$ allele, $95 \% \mathrm{Cl}$ $=1.470-1.734, \mathrm{P}$ value $=0.000$ for $\mathrm{G}$ vs $\mathrm{C}$ ), and the $\mathrm{G}$ allele of the polymorphism could increase the risk for AMD. Analysis under the dominant and additive genetic models also yielded significant results for the rs2230199 SNP (dominant model: pooled $\mathrm{OR}=1.681,95 \% \mathrm{Cl}=1.521-1.858, \mathrm{P}$ value $=0.000$ for $\mathrm{GG}+\mathrm{CG}$ vs CC; additive model: pooled $\mathrm{OR}=1.571,95 \% \mathrm{Cl}=1.414-1.745, \mathrm{P}$ value $=0.000$ for CG vs CC) (Table 2).

In the stratified analysis by ethnicity, there was also a significant positive correlation between the rs2230199 SNP and AMD susceptibility in Caucasians $(\mathrm{OR}=1.600,95 \% \mathrm{Cl}=1.472$ 1.739, $\mathrm{P}=0.000$ for $\mathrm{G}$ vs $\mathrm{C}$ under the allelic model; $\mathrm{OR}=1.689,95 \% \mathrm{Cl}=1.526-1.869, \mathrm{P}=0.000$ for $\mathrm{GG}+\mathrm{CG}$ vs $\mathrm{CC}$ under the dominant model; $\mathrm{OR}=2.106,95 \% \mathrm{Cl}=1.699-2.610, \mathrm{P}=0.000$ for $\mathrm{GG}$ vs $\mathrm{CC}+\mathrm{CG}$ under the recessive model; and $\mathrm{OR}=1.601,95 \% \mathrm{Cl}=1.279-2.005, \mathrm{P}=0.000$ for $\mathrm{GG}$ vs $\mathrm{CG}$ and $\mathrm{OR}=1.576,95 \% \mathrm{Cl}=1.417-1.753, \mathrm{P}=0.000$ for $\mathrm{CG}$ vs $\mathrm{CC}$ under the additive model) (Table 2). However, analysis of Asian samples did not result in a significant correlation using any genetic model (pooled $\mathrm{OR}=1.364,95 \% \mathrm{Cl}=0.692-2.688, \mathrm{P}$ value $=0.369$ for $\mathrm{G}$ vs $\mathrm{C}$ under the allelic model; pooled $\mathrm{OR}=1.368,95 \% \mathrm{Cl}=0.692-2.704, \mathrm{P}$ value $=0.367$ for $\mathrm{GG}+\mathrm{CG}$ vs $\mathrm{CC}$ under the dominant model; and pooled $\mathrm{OR}=1.368,95 \% \mathrm{Cl}=0.692-2.704, \mathrm{P}$ value $=0.367$ for $\mathrm{CG}$ vs $\mathrm{CC}$ under the additive model) (Table 2). Among 5 studies done in Asian populations, there were no patients with the GG genotype; thus, data were insufficient for assessing genetic effects. The forest plot of the meta-analysis in all samples under the dominant model is presented in Figure 2. For the meta-analysis, no statistically significant heterogeneity was observed in the total, Caucasian, or Asian samples under any genetic model (Table 2). 


Study
ID

Figure 2. Forest plot for the rs2230199 $C>G$ polymorphism and risk of $A M D$ in overall populations using the dominant model (GG+CG vs CC). The squares and horizontal lines correspond to the study-specific OR and $95 \% \mathrm{Cl}$, respectively. The area of the squares reflects the weight (inverse of the variance). The diamond represents the $\mathrm{OR}$ and $95 \% \mathrm{Cl}$ of the summary.

Table 2. Main results of meta-analysis on the association between the rs2230199 polymorphism and age-related macular degeneration risk.

\begin{tabular}{|c|c|c|c|c|c|c|}
\hline \multirow[t]{2}{*}{ Variables } & \multicolumn{2}{|c|}{ Test of association } & \multirow[t]{2}{*}{ Z-score } & \multicolumn{2}{|c|}{ Test of heterogeneity } & \multirow[t]{2}{*}{ Statistical model } \\
\hline & OR $(95 \% \mathrm{Cl})$ & $P$ & & $P_{\mathrm{h}}$ & $1^{2}$ & \\
\hline \multicolumn{7}{|l|}{$\mathrm{G}$ vs $\mathrm{C}$} \\
\hline Total & $1.597(1.470-1.734)$ & 0.000 & 11.09 & 0.968 & $0.0 \%$ & Fixed \\
\hline Caucasian & $1.600(1.472-1.739)$ & 0.000 & 11.07 & 0.937 & $0.0 \%$ & Fixed \\
\hline Asian & $1.364(0.692-2.688)$ & 0.369 & 0.90 & 0.713 & $0.0 \%$ & Fixed \\
\hline \multicolumn{7}{|c|}{$\mathrm{GG}+\mathrm{CG}$ vs $\mathrm{CC}$} \\
\hline Total & $1.681(1.521-1.858)$ & 0.000 & 10.17 & 0.972 & $0.0 \%$ & Fixed \\
\hline Caucasian & 1.689 (1.526-1.869) & 0.000 & 10.14 & 0.954 & $0.0 \%$ & Fixed \\
\hline Asian & $1.368(0.692-2.704)$ & 0.367 & 0.90 & 0.710 & $0.0 \%$ & Fixed \\
\hline \multicolumn{7}{|c|}{$\mathrm{GG}$ vs $\mathrm{CC}+\mathrm{CG}$} \\
\hline \multicolumn{7}{|c|}{ Total } \\
\hline Caucasian & $2.106(1.699-2.610)$ & 0.000 & 6.79 & 0.718 & $0.0 \%$ & Fixed \\
\hline \multicolumn{7}{|l|}{ Asian } \\
\hline \multicolumn{7}{|l|}{ GG vs CG } \\
\hline \multicolumn{7}{|l|}{ Total } \\
\hline Caucasian & $1.601(1.279-2.005)$ & 0.000 & 4.10 & 0.656 & $0.0 \%$ & Fixed \\
\hline \multicolumn{7}{|l|}{ Asian } \\
\hline \multicolumn{7}{|l|}{ CG vs CC } \\
\hline Total & $1.571(1.414-1.745)$ & 0.000 & 8.42 & 0.964 & $0.0 \%$ & Fixed \\
\hline Caucasian & $1.576(1.417-1.753)$ & 0.000 & 8.39 & 0.926 & $0.0 \%$ & Fixed \\
\hline Asian & $1.368(0.692-2.704)$ & 0.367 & 0.90 & 0.710 & $0.0 \%$ & Fixed \\
\hline
\end{tabular}

$\mathrm{OR}=$ odds ratio $; \mathrm{Cl}=$ confidence interval; $P_{\mathrm{h}}: \mathrm{P}$ value of Q-test for heterogeneity test. 


\section{Sensitivity analysis}

In order to compare the differences and evaluate the sensitivity of the meta-analyses, we conducted a one-way sensitivity analysis to evaluate the stability of the meta-analysis. The resultant pattern was not impacted by a single study in all genetic models, for example, under the additive model (CG vs CC), which is shown in Figure 3.

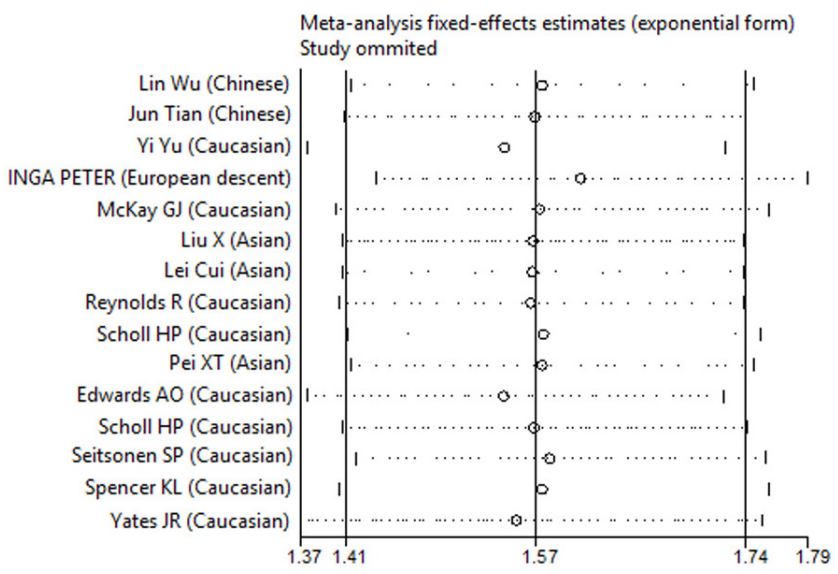

Figure 3. Sensitive analysis of the C3 rs2230199 polymorphism illustrating the influence of each study on pooled OR under the additive model (CG vs CC).

\section{Publication bias}

Begg's funnel plot and Egger's test were performed to assess the publication bias of the literature used in this study. The shapes of the funnel plots did not reveal any evidence of obvious asymmetry in all comparison models. Furthermore, Egger's test was used to provide statistical evidence for funnel plot symmetry (Figure 4). The results still did not suggest any publication bias.

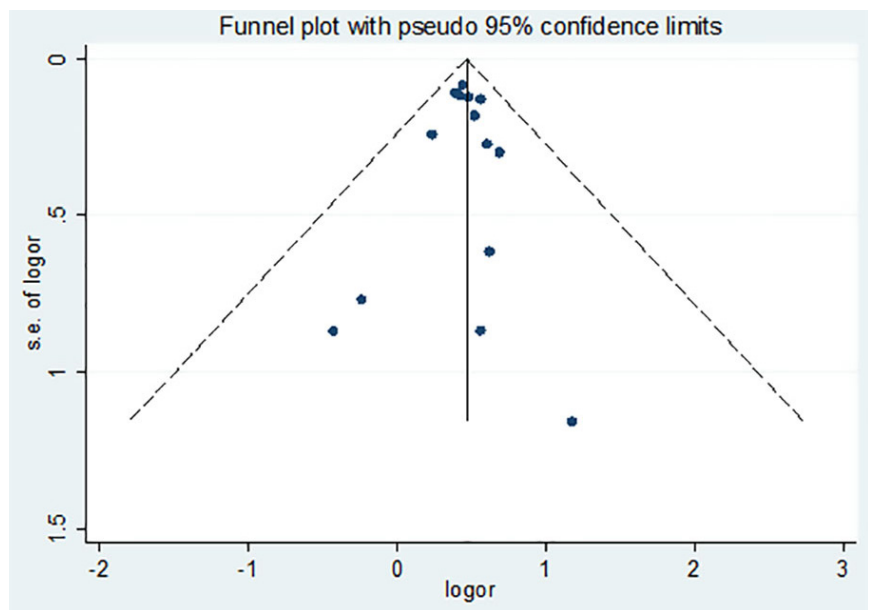

Figure 4. Funnel plot for assessing the publication bias using the allele contrast model ( $\mathrm{G}$ allele vs $\mathrm{C}$ allele). 


\section{DISCUSSION}

AMD accounts for more than $54 \%$ of all vision loss in Caucasians in the USA (Congdon et al., 2004) (Group, 2004). It is widely acknowledged that genetics play an important role in the development of AMD. SNPs are the most common form of human genetic variation that may contribute to an individual's susceptibility to some diseases (Yu and Chen, 2012). It is important to identify the SNPs that affect gene function contributing to AMD susceptibility in order to better predict individual risk and understand the pathogenesis of AMD.

To date, a growing number of studies suggest that the rs2230199 polymorphism is associated with an increased susceptibility to AMD. However, the results have been conflicting, even within populations. Meta-analysis, a statistical tool for combining the results of literature across studies, is becoming popular as a method for resolving discrepancies in genetic association studies (Munafo and Flint, 2004). Hence, we used this method to demonstrate the association between the rs2230199 polymorphism and AMD susceptibility.

The present meta-analysis, including 5593 cases and 5181 controls of 15 independent case-control studies, concerned the rs2230199 polymorphism of the C3 gene and AMD risk. The results of our meta-analysis study indicate that the rs2230199 C > G SNP increased the risk of AMD development and that the rs2230199 $\mathrm{G}$ allele was a risk factor for AMD in Caucasians but not Asians. In addition, the frequency of the rs2230199 G allele in Caucasian populations was higher than in Asians, which is consistent with our results. Therefore, the rs2230199 G allele could be considered as a biomarker for AMD. In comparison to previous meta-analyses, our analysis included a greater number of studies and this larger sample size increased the statistical power of the result obtained. Moreover, the present meta-analysis included an acceptable quality evaluation system, minimizing the potential for bias.

The human C3 gene is located on chromosome 19 and exhibits nine common genetic SNPs. The association between SNPs in the C3 gene and AMD susceptibility has been established in multiple studies (Maller et al., 2007; Spencer et al., 2008; Park et al., 2009; Liu et al., 2010). Rs2230199 is a SNP in the C3 gene, which is a central component of all three pathways of complement activation - the alternative, classical, and mannose binding lectin pathways. All of these pathways lead to the cleavage of C3 into biologically active C3a and C3b fragments (Ricklin et al., 2010). Genetic studies have identified an important role for the complement cascade in the pathogenesis of AMD (Ding et al., 2009; Anderson et al., 2010); various complement-related molecules have been found in drusen and neighboring RPE (Ding et al., 2009). Dysfunction in the complement pathway has been proposed to increase retinal cell damage via increased formation of drusen deposits, atrophy, and cell degeneration and progression to choroidal neovascularization (Anderson et al., 2002; Hageman et al., 2005).

Some limitations of our meta-analysis should be acknowledged. First, the number of published studies collected in our analysis was not sufficiently large enough, particularly for studies focused on Asian and African populations. Second, gene-gene and gene-environment interactions were not well analyzed. There is no doubt that specific environmental and lifestyle factors may alter the association between C3 gene polymorphisms and AMD susceptibility, including age, smoking and familial history. Moreover, there are three different developmental stages for AMD, including early AMD, exudation, and geographic atrophy. Future studies should analyze these subgroups to better explain the SNPs in the C3 gene that are involved in AMD development. Nevertheless, advantages in our meta-analysis should also be acknowledged. First, a systematic review of the 
association of the C3 rs2230199 polymorphism with AMD risk is statistically more powerful than any single case-control or cohort study. Second, the studies included in our meta-analysis strictly and satisfactorily met our selection criteria.

In conclusion, our present meta-analysis suggests that the rs2230199 C > G SNP in the C3 gene may be associated with AMD risk. In addition, further studies using larger sample sizes and considering gene-environment interactions should be conducted to examine this association more comprehensively.

\section{Conflicts of interest}

The authors declare no conflict of interest.

\section{ACKNOWLEDGMENTS}

Research supported by the National 863 High-Technology Research and Development Program (\#2012AA02A519) and the State Project for Essential Drug Research and Development (Grant \#2012ZX09506001007).

\section{REFERENCES}

Anderson DH, Mullins RF, Hageman GS and Johnson LV (2002). A role for local inflammation in the formation of drusen in the aging eye. Am. J. Ophthalmol. 134: 411-431.

Anderson DH, Radeke MJ, Gallo NB, Chapin EA, et al. (2010). The pivotal role of the complement system in aging and agerelated macular degeneration: hypothesis re-visited. Prog. Retin. Eye Res. 29: 95-112.

Congdon N, O'Colmain B, Klaver CC, Klein R, et al. (2004). Causes and prevalence of visual impairment among adults in the United States. Arch. Ophthalmol. 122: 477.

Cui L, Zhou H, Yu J, Sun E, et al. (2010). Noncoding variant in the complement factor $\mathrm{H}$ gene and risk of exudative age-related macular degeneration in a Chinese population. Invest. Ophthalmol. Vis. Sci. 51: 1116-1120.

De Jong PT (2006). Age-related macular degeneration. N. Engl. J. Med. 355: 1474-1485.

DerSimonian R and Laird N (1986). Meta-analysis in clinical trials. Control. Clin. Trials 7: 177-188.

Ding X, Patel M and Chan CC (2009). Molecular pathology of age-related macular degeneration. Prog. Retin. Eye Res. 28: 1-18.

Duvvari MR, Paun CC, Buitendijk GH, Saksens NT, et al. (2014). Analysis of rare variants in the C3 gene in patients with agerelated macular degeneration. PloS One 9: e94165.

Edwards AO, Fridley BL, James KM, Sharma AK, et al. (2008). Evaluation of clustering and genotype distribution for replication in genome wide association studies: the age-related eye disease study. PLoS One 3: e3813.

Gehrs KM, Jackson JR, Brown EN, Allikmets R, et al. (2010). Complement, age-related macular degeneration and a vision of the future. Arch. Ophthalmol. 128: 349-358.

Gold B, Merriam JE, Zernant J, Hancox LS, et al. (2006). Variation in factor B (BF) and complement component 2 (C2) genes is associated with age-related macular degeneration. Nat. Genet. 38: 458-462.

Hageman GS, Anderson DH, Johnson LV, Hancox LS, et al. (2005). A common haplotype in the complement regulatory gene factor $\mathrm{H}(\mathrm{HF} 1 / \mathrm{CFH})$ predisposes individuals to age-related macular degeneration. Proc. Natl. Acad. Sci. U. S. A. 102: 7227-7232.

Liu X, Zhao P, Tang S, Lu F, et al. (2010). Association study of complement factor H, C2, CFB, and C3 and age-related macular degeneration in a Han Chinese population. Retina 30: 1177-1184.

Maller JB, Fagerness JA, Reynolds RC, Neale BM, et al. (2007). Variation in complement factor 3 is associated with risk of age-related macular degeneration. Nat. Genet. 39: 1200-1201.

Mantel N and Haenszel W (1959). Statistical aspects of the analysis of data from retrospective studies of disease. J. Natl. Cancer Inst. 22: 719-48.

McKay GJ, Dasari S, Patterson CC, Chakravarthy U, et al. (2010). Complement component 3: an assessment of association with AMD and analysis of gene-gene and gene-environment interactions in a Northern Irish cohort. Mol. Vis. 16: 194

Mousavi M and Armstrong RA (2013). Genetic risk factors and age-related macular degeneration (AMD). J. Optom. 6: 176-184. 
Munafò MR and Flint J (2004). Meta-analysis of genetic association studies. Trends Genet. 20: 439-444.

Park KH, Fridley BL, Ryu E, Tosakulwong N, et al. (2009). Complement component 3 (C3) haplotypes and risk of advanced age-related macular degeneration. Invest. Opthamol. Vis. Sci. 50: 3386-3393.

Pei XT, Li XX, Bao YZ, Yu WZ, et al. (2009). Association of c3 gene polymorphisms with neovascular age-related macular degeneration in a chinese population. Curr. Eye Res. 34: 615-622.

Peter I, Huggins GS, Ordovas JM, Haan M, et al. (2011). Evaluation of new and established age-related macular degeneration susceptibility genes in the Women's Health Initiative Sight Exam (WHI-SE) Study. Am. J. Opthamol. 152: 1005-1013. e1001.

Raychaudhuri S, lartchouk O, Chin K, Tan PL, et al. (2011). A rare penetrant mutation in CFH confers high risk of age-related macular degeneration. Nat. Genet. 43: 1232-1236.

Resnikoff S, Pascolini D, Etya'ale D, Kocur I, et al. (2004). Global data on visual impairment in the year 2002. Bull. World Health Organ. 82: 844-851.

Reynolds R, Hartnett ME, Atkinson JP, Giclas PC, et al. (2009). Plasma complement components and activation fragments: associations with age-related macular degeneration genotypes and phenotypes. Invest. Opthamo. Vis. Sci. 50: 5818-5827.

Ricklin D, Hajishengallis G, Yang K and Lambris JD (2010). Complement: a key system for immune surveillance and homeostasis. Nat. Immunol. 11: 785-797.

Scholl HP, Charbel Issa P, Walier M, Janzer S, et al. (2008). Systemic complement activation in age-related macular degeneration. PloS One 3: e2593.

Scholl HP, Fleckenstein M, Fritsche LG, Schmitz-Valckenberg S, et al. (2009). CFH, C3 and ARMS2 are significant risk loci for susceptibility but not for disease progression of geographic atrophy due to AMD. PLoS One 4: e7418.

Seddon JM, Yu Y, Miller EC, Reynolds R, et al. (2013). Rare variants in CFI, C3 and C9 are associated with high risk of advanced age-related macular degeneration. Nat. Genet. 45: 1366-1370.

Seitsonen SP, Onkamo P, Peng G, Xiong M, et al. (2008). Multifactor effects and evidence of potential interaction between complement factor $\mathrm{H} \mathrm{Y402H}$ and LOC387715 A69S in age-related macular degeneration. PloS One 3: e3833.

Spencer KL, Olson LM, Anderson BM, Schnetz-Boutaud N, et al. (2008). C3 R102G polymorphism increases risk of agerelated macular degeneration. Hum. Mol. Genet. 17: 1821-1824.

Tian J, Yu W, Qin X, Fang K, et al. (2012). Association of genetic polymorphisms and age-related macular degeneration in Chinese population. Invest. Opthamol. Vis. Sci. 53: 4262-4269.

Vingerling JR, Dielemans I, Hofman A, Grobbee DE, et al. (1995). The prevalence of age-related maculopathy in the Rotterdam Study. Ophthalmology 102: 205-210.

Wu L, Tao Q, Chen W, Wang Z, et al. (2013). Association between polymorphisms of complement pathway genes and agerelated macular degeneration in a Chinese population. Invest. Opthamol. Vis. Sci. 54: 170-174.

Yanagisawa S, Kondo N, Miki A, Matsumiya W, et al. (2011). A common complement C3 variant is associated with protection against wet age-related macular degeneration in a Japanese population. PloS One 6: e28847.

Yates JR, Sepp T, Matharu BK, Khan JC, et al. (2007). Complement C3 variant and the risk of age-related macular degeneration. N. Engl. J. Med. 357: 553-561

Yu L and Chen J (2012). Association of MTHFR Ala222Val (rs1801133) polymorphism and breast cancer susceptibility: An update meta-analysis based on 51 research studies. Diagn. Pathol. 7: 171.

Yu Y, Reynolds R, Fagerness J, Rosner B, et al. (2011). Association of variants in the LIPC and ABCA1 genes with intermediate and large drusen and advanced age-related macular degeneration. Invest. Opthamol. Vis. Sci. 52: 4663-4670.

Zintzaras E and loannidis JP (2005). Heterogeneity testing in meta-analysis of genome searches. Genet. Epidemiol. 28: $123-137$. 